\title{
Alessandra Molinari
}

\author{
Università di Urbino
}

\section{A Crease in Gathering 17 of Bodleian MS. Junius 11}

doi: 10.7358/ling-2014-002-moli

alessandra.molinari@uniurb.it

Invited article

Junius 11 (Oxford, Bodleian Library) is one of the most important Anglo-Saxon manuscripts. This volume is unique in many respects. It is the only volume wholly dedicated to Old English biblical verse. It is the only Anglo-Saxon poetic manuscript containing an illustration cycle. It is the first Anglo-Saxon poetic manuscript which was printed. And it is the only codex which was credited to Cædmon, the legendary founder of Old English poetry.

This codex unicus was produced in Canterbury or Malmesbury in the late $10^{\text {th }}$ century ${ }^{1}$. It has 17 gatherings ${ }^{2}$. They contain a verse sequence of four biblical poems which were identified by philologists on the grounds of their different lexicon, metrics, style and textuality. Few visual hints help distinguish

1 Literature on MS Junius 11 reaches back into the beginnings of Anglo-Saxon scholarship. Here only a selection from works with significant insights into codicological issues or with a valuable summary of scholarship on the manuscript can be proposed. S. Stoddard (1888); Clubb (1925); Gollancz (1927); Krapp (1931); Timmer (1948); Ker (1957); Raw (1976); Finnegan (1977); Lucas (1977); Doane (1978); Lucas (1979); Raw ([1984] 1994); O’Brian O’Keeffe (1990); Doane (1991); Pasternack (1995) Remley (1996); Karkov (2001); Lockett (2002); Muir (2004); and Doane (2013). As for dating, scholarship widely accepts Lockett's $(2002,158 ; 172-173)$ view that the codex was incepted from about 960 on and that its production was carried on until no earlier than the first years of the eleventh century. The story of Cædmon is narrated in Bedes Historia Ecclesiastica Gentis Anglorum, liber iv, cap. xxiv. In the deep belief that the manuscript we are dealing with contains Cædmon's original poetry, the Dutch philologist, theologian and art historian Franciscus Junius published it in 1655 as the first printed edition ever of Old English verse, with the title Cxdmonis Monachi Paraphrasis Poetica Genesios ac præcipuarum Sacræ Paginx Historiarum [...] (s. Lucas 2000). However, it has long been recognized that the poems of Junius 11 are by different authors.

2 The 17 gatherings are made up of 116 folios, paged i, ii, 1-230. Pp. 1-229 were paged by Franciscus Junius, p. 230 was numbered later; therefore many scholars refer to it as (230) - as will be the case in the present study - or [230]. A number of leaves and several entire sheets are lost; they were cut off the manuscript long before Junius paged it. For a physical description of the manuscript s. especially Stoddard (1888), Ker (1957, 406-409), Raw ([1984] 1994), Lockett (2002), Muir (2004) and Doane (2013,1-35). 
these poems from one another because on the whole the manuscript layout and physical make-up look quite homogeneous ${ }^{3}$. There is however a break in such a uniformity. The last gathering differs from the first 16 in many respects. Gatherings 1 to 16 were originally quires of eight leaves and most of them still are; gathering 17 contains ten leaves and its original structure has long been a matter of dispute. The ruling of all quires except gathering 17 is uniform; the ruling of gathering 17 varies within the gathering itself. Sectional divisions are numbered from I to LV through the first 16 gatherings up to p. 209 in gathering 17; the numbering of the sections starts anew at p. 213 in the same gathering ${ }^{4}$. A single hand has written the text in the first 16 gatherings up to p. 212 in gathering 17; from p. 213 on two or three different hands are recognizable. Given these differences, scholarship has referred to the two portions of the manuscript as Liber I (gatherings 1 to 17 up to p. 212) and Liber II (gathering 17 from p. 213 to p. 229) ${ }^{5}$.

Between Liber I and Liber II there is also a thematic difference. The poems contained in Liber I - Genesis A and B, Exodus and Daniel - deal with Old Testament narratives; the poem contained in Liber II, Christ and Satan, relates to the New Testament. This fact, together with the codicological and layout distinctions mentioned above, has raised some questions as to the codicological and bibliographic unity of MS Junius 11 . Scholarship has focussed on the origin, dating and structure of gathering 17 and on its relationship to the other gatherings. Two questions have been at stake. First, whether gathering 17 or at least the leaves in it containing Christ and Satan were part of the original editorial plan ${ }^{6}$; second, whether the leaves in gathering 17 that contain Christ and

3 Spaces were almost surely left for illustrations throughout the manuscript (Raw [1984] 1994, 254; $256 ; 261-263 ; 270$ ). Metrical punctuation as originally inserted looks consistent along all poems (Krapp 1931, xxii-xxiii), save that by a closer analysis the scribes of Christ and Satan seem not to have shared the same concept of the function of pointing as the scribe of the first three poems (O'Brian O'Keeffe 1990, 181-187;), so that their pointing was corrected by another hand; furthermore, many of the metrical points in Christ and Satan were later turned into positurae (Thornley 1954, 188-189). On the origin of punctuation in Junius 11 s. Lockett's $(2002,167-172)$ ground-breaking analysis. Even though the use of accents looks uniform throughout the volume (Thornley 1954, passim), I do not consider them here because they were partly added later, so that we cannot use them as evidence for the planning of Junius 11 as a self-contained whole from its very outset. On points and accents in Junius 11 s. also Doane (2013, 23-25). A rationale for the use of zoomorphic and plain capitals is recognizable from the beginning to the end of the written sequence, including the last poem (Doane 2103, 19).

4 Some sections are not explicitly numbered, but the numbering sequence itself remains consistent.

5 At the end of Christ and Satan (gathering 17, p. 229) the scribe wrote Finit Liber II. Amen. Accordingly, scholars have posited a corresponding statement Finit Liber I. Amen at the supposed end of Daniel, which probably went lost when a bifolium was cut off the same gathering between pp. 212 and 213 (and between pp. 228 and 229). At present the last line of Daniel is at the bottom of p. 212. Most scholars nowadays agree that this last line is not the end of the poem. S. below, par. 2 in the present study.

6 The questions of the bibliographic unity of the manuscript and of an organizing principle behind 
Satan ever had a separate existence as a self-contained codicological unit, i.e as a booklet, before they were inserted into the gathering. The booklet thesis was conceived by Lucas (1979) on the grounds of some codicological features, among them the presence of a horizontal crease inside the gathering.

In the present study I will strengthen the case that the leaves containing Christ and Satan were not conceived as an independent booklet and show that the crease in the middle of those leaves cannot be taken as evidence for the booklet thesis. As a consequence, Junius 11 may not be defined as a composite manuscript ${ }^{7}$. A brief description of gathering 17 will serve as an introduction.

\section{GATHERING 17}

In its present state, gathering 17 looks like a quinion of four sheets and two singletons, its leaves being paged 211 to (230). At the bottom of p. 212 the poem Daniel ends abruptly; on top of p. 213 Christ and Satan begins. Marks of knife cutting on p. 212 strongly suggest that between those pages one leaf containing the end of Daniel is missing ${ }^{8}$; probably it was a whole sheet originally placed between pp. 212 and 213 and between pp. 228 and 229 which went lost ${ }^{9}$. Two narrow parchment stubs between pp. 216-217 and between pp. 222-223 conjoined with pp. 223-224 and pp. 217-218 respectively point at two further missing leaves, even though there is no apparent gap in the text of Christ and Satan at those points. Most scholars agree that gathering 17 must have once had the following structure:

its compilation have been discussed mainly by Gollancz (1927, xcviii-xcix), Allen (1976), Hall (1976), Finnegan (1977, 4), Lucas (1979), Raw ([1984] 1994), Hall (1986), O’Brian O'Keeffe (1990, 179-197), Portnoy (1994), Pasternack (1995, 179-194), Hall (2002), Remley (1996, 20-24; 66-67 et passim), Hall (2002), Lockett (2002, 142 n. 4) and Doane (2013, 2f.; 18-20 et passim). For an overview on older scholarship on these issues s. Hill ([1992] 2002).

7 In the present study I understand the term composite volume or composite manuscript in the sense outlined by Robinson ([1978] 1994, 25), s. below. For a claim of Junius 11 as a composite volume s. Conner ([1986] 1994, 315) and O'Brian O'Keeffe (1990, 179).

8 Stoddard (1888, 159; 162-163), Gollancz (1927, xcviii-xcix), Ker (1957, 407-408), Hall (1986, 104 n. 4), Lucas (1979, 47-58), Raw ([1984] 1994, 261-263 et passim) and Campbell (1988, 13-16) share this view against Farrell (1974, 5-6); Pasternack (1995, 190-191) takes on an intermediate position. They draw their arguments from codicology, textuality and source studies.

9 Further evidence for the loss of a leaf or a bifolium at this point comes from a smudged note in a 12th-century hand on p. 212 for which there is no offset on the opposite page: presumably the offset was on one page of the now missing bifolium (Raw [1984] 1994, 261). Raw (ibid., 233; 271 et passim) suggests that the lost bifolium was originally meant to contain full page illustrations. 


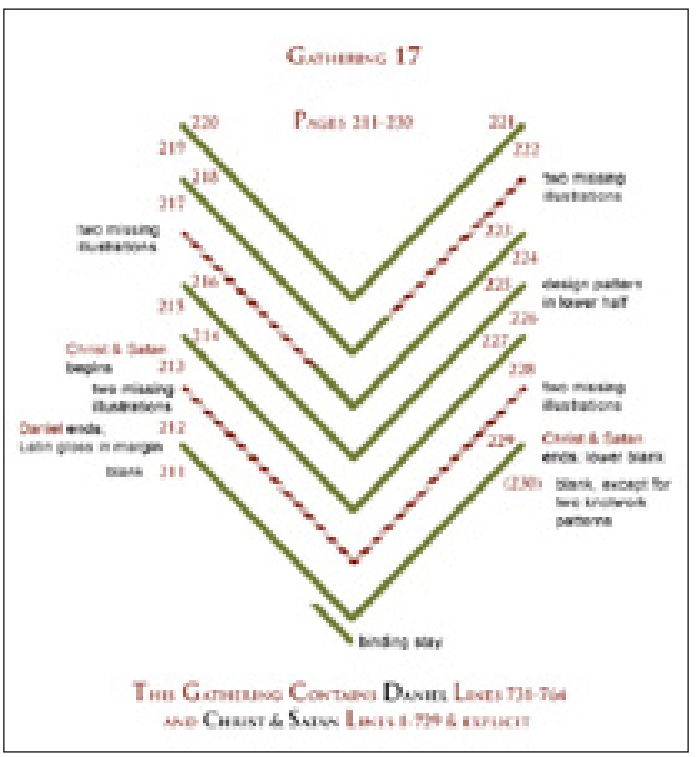

Fig. 1 - MS. Junius 11, Gathering 17. From Muir 2004, "Diagrams of gatherings" 10.

Inside gathering 17 some differences are notable at first sight. Pp. 211/212 were ruled for and written with 26 lines on a page, like most pages in Liber I. On the other leaf of the same sheet, p. 229 is ruled for and written with 27 lines on a page (whereas p. (230) is left blank); pp. 213 to 228 are ruled for and written with 27 lines. Ker gives the following explanation for such an internal inconsistency of the gathering:

The differences in ruling between the first leaf of quire 17 and the rest of the quire, and the fact that there is a break in the text between p. 212 and 213 which is not apparent from the collation [i.e. that between Daniel and Christ and Satan], are explicable if the quire, though formally a quinion, is really a quaternion (pp. 213-28) inserted into the outside sheet of an older quire (pp. 211-12, 229-30) in place of cancelled or missing leaves, the originally blank second leaf of this sheet being used to receive the part of the text which would not fit into the quaternion. (Ker 1957, 408)

Lucas (1979) supports Ker's view by pointing to a horizontal crease affecting all the leaves of the quaternion of pp. 213-28 at the height of line $16^{11}$. In

10 Reproduced from Muir (2004) with the courtesy of the Bodleian Library.

11 The crease has been noticed by Clubb (1925, xv), Gollancz (1927, xcic), Finnegan (1977, 4), but not by $\operatorname{Ker}(1957,406-408)$. 
Lucas's eyes (ibid., 47-49), the pricking and ruling on pp. 213-28 (that is, on the pages containing Christ and Satan) and the presence of the crease on pp. 213-228 are evidence that the quaternion (pp. 213-28) was originally "a folded booklet of the type described by Bischoff" (ibid., 49) ${ }^{12}$ :

Evidently our only surviving text of Christ and Satan (that is, strictly, the text as far as line 709) began its life as a folded booklet. [...] At some time probably in the second quarter of the eleventh century [i.e. according to Lucas, the date of the binding] it was decided to unfold the booklet containing Christ and Satan and incorporate it into the last quire of what is now MS Junius 11. [...]. As part of the process of incorporation the ending of Christ and Satan (lines 710-29) was re-written on the first page of the originally blank second leaf (p. 229) of the outer sheet (leaves 1 and 10) and the final singleton leaf (or outer sheet) of the original folded booklet discarded. (Lucas 1979, 51-52)

Raw ([1984] 1994, 252-69) rejects Lucas's conclusion and claims that the part of the gathering containing Christ and Satan never existed as a self-contained booklet circulating independently of the main manuscript. She produces three arguments against Lucas, which are to be summarized here.

First, she makes the important discovery that Junius 11 was stitched twice - once right after Christ and Satan was set down into the manuscript, and a second time, together with the present binding, in the early $13^{\text {th }}$ century - and shows that Christ and Satan "was included in the manuscript as originally sewn and that it has not been sewn independently [...]". This "suggests very strongly that it was not originally a separate manuscript (as Lucas has argued)." (ibid., 263). Thus, "if this text had an earlier, independent existence, as Lucas has claimed, it was used unstitched." (ibid., 254) ${ }^{13}$.

Second, she is able to confute Lucas's analysis of the gathering pricking and ruling. According to her study, the real division in the gathering is not between the outer bifolium (pp. 211/212 and 229/(230)) and the inner part (pp. 213-28); although she concedes that the inner part of the gathering looks very different from the outer bifolium, she defines this difference as superficial (ibid., 267). In her study she argues that "the real division is between the outer three bifolia (pp. 211-16 and 225-9) and the inner sheets (pp. 217-24)" (ibid., 268). As she can show, the three outer bifolia (pp.211/212 and 229/230; pp. $213 / 214$ and 227/228; pp. 215/216 and 225/226) were pricked in both margins

12 S. below, paragraph 2 in the present study.

13 For the sake of precision, it should be acknowledged that this argument is weaker than that of the pricking and ruling. The fact that the folded pages of Christ and Satan were first stitched together with the rest of the manuscript does not prevent those pages from having possibly circulated for a while as an independent booklet, it just makes it less plausible. From Bischoff's and Robinson's evidence, it does not follow that booklets were necessarily stitched. S. also Remley (1996, 21 n. 32). 
like those in the rest of the manuscript, whereas the other sheet and singletons, as far as this is still visible, were pricked in the outer margins only; moreover, the pricking for the vertical ruling shows that pp. 213-16 and 225-8 were intended to have a narrower writing-area than that now filled with writing, in fact prick-holes on those leaves correspond exactly to the prick-holes on the outer sheet of the gathering. By contrast, the inner leaves (pp. 217-222) share another pricking layout. Drawing on this and other evidence from pricking Raw ([ibid., 268) concludes that the three outer bifolia of gathering 17, now containing a part of Christ and Satan (1l. 1-170 in pp. 213-216 and 1l. 528-729 in pp. 225229), "were pricked simultaneously and formed part of the original gathering prepared for the end of Daniel, whereas the inner leaves (pp. 217-222) did not." As for the ruling, Raw (ibid., 269) argues that if pp. 213-28 were originally an independent manuscript, they should have been pricked and ruled together; in particular, the primary ruling for the gathering ought to be found on p. 213, the outer bifolium of the supposed separate manuscript. By contrast, Raw (ivi) points out that the ruling on p. 213 is very faint apart from the bottom line 27 and that the top twenty-six lines of this page are perfectly level with the corresponding lines on page 212. In other words, pp. 212 and 213 were not only pricked but also ruled together. As for the central leaves (pp. 217-224), the vertical rulings of some of the pages are so diverging from one another and from the pages in the outer leaves, that it is clear in Raw's (ivi) eyes that the central pages cannot have been ruled at the same time as the outer three bifolia of the gathering. On the grounds of the ruling, too, Raw (ivi) therefore concludes that "the outer three bifolia of the last gathering were prepared in connection with the end of Daniel, whereas the inner singletons and bifolium were inserted when Christ and Satan was added to the manuscript [...]."

Raw's third argument against Lucas concerns the crease along line 16 of pp. 213-228, which is used by Lucas as a second piece of evidence for his booklet thesis after the evidence from stitching and ruling. Raw's analyis of the crease (s. below, par. 3 in the present study) helps reject the booklet thesis, too, but it is treated by her as mere circumstantial evidence. In the following paragraphs I will strengthen the case for the crease as evidence against the booklet thesis by supporting Raw's analysis with new details and by showing that Lucas's arguments about the crease as positive evidence for a booklet are too weak to hold.

Before this let us briefly focus on Lucas's reference to Bischoff's (1966) understanding of what a booklet is. I also would like to refer to Robinson's ([1978] 1994, 25-36) seminal study, which draws on Bischoff and helps me put my arguments into a proper frame ${ }^{14}$.

14 Further selected literature on booklets is Robinson (1980), Hanna III (1986), Gumberth (2004). 


\section{ON EARLY MEDIEVAL BOOKLETS}

Bischoff's article (1966) is a survey of Latin booklets from the early Middle Ages. Three main criteria for identifying booklets can be inferred from his survey. First, booklet texts were by their nature destined to circulate and were not long. Bischoff $(1966,94)$ lists the following text types: homilies; hagiographies; school texts; literary texts; discliplinary and ascetic texts; and medical treatises. Second, as all examples dealt with by Bischoff are folded across the middle of their pages or down it or both, the presence of one or more folds or creases (perpendicular to one another) and a bad state of the parchment around the folds of the outer leaf seem to be characteristic of booklets. In fact, they are defined by Bischoff (ibid, p. 93) as gefaltete Handschriften, 'folded manuscripts', as the title itself of the article reveals. Third, booklets are not preserved independently: they were bound into bigger manuscripts in the Middle Ages or later, in any case after they had been circulating as folded units for a while. They are recognizable through their gatherings having a page layout or handwriting different from the rest of the manuscript.

In her study of vernacular booklets, Robinson develops some of Bischoff's tenets and comes to a clear definition: a booklet is a "self-contained unit[...]" which "originated as a small but structurally independent production containing a single work or a number of short works." (Robinson [1978] $1994,25)$. She then gives a list of features which help to identify a booklet in an Anglo-Saxon composite volume (ibid., pp. 26-27). Here I report only those features which are relevant to our discussion on gathering 17 of Junius $11^{15}$ :

1. The beginning and end of a booklet always coincide with the beginning and end of a text or group of texts.

[...]

3. Its handwriting may differ; where its handwriting is contemporary with other handwriting in the manuscript, differences in habits in setting out text on the page may help to distinguish one booklet from others in the same volume.

4. Its style of decoration may differ.

[...]

6. Its outer pages may be soiled or rubbed.

7. Its number of leaves to a quire may differ from the number(s) in other parts of the manuscript. (Robinson 1978 [1994], 27).

Significantly enough, Robinson's list does not contain any reference to folding; rather, her concern (ivi) is that "[i]t must be emphasized that the existence of

15 It is notable that Robinson does not include the folded pages of Christ and Satan among her evidence. 
a booklet is established only if its content forms a self-sufficient unit". In other words, in a booklet the self-contained content and the originally independent structure are two sides of the same coin.

Given Bischoff's and Robinson's criteria and Robinson's definition, it is clear that pp. 213-228 containing Christ and Satan in gathering 17 cannot be considered as a booklet. In fact, this portion of the gathering did not originate as a structurally independent production. As Raw (s. above) has shown, when the beginning of Christ and Satan was set down onto pp. 213-216, these pages, together with pp. 225-229, had already been pricked and ruled in connection with Daniel according to the layout of Liber I. They did not originate independently. When Christ and Satan was written down, their writing space was enlarged, in order that they might contain as much verse of this poem as possible, by adapting their layout to the layout of the newly added leaves corresponding to pp. 217-224. We cannot consider the added pp. 217-224 as a booklet, either. In fact, their textual content does not represent a self-sufficient unit ${ }^{16}$. Thus, feature 1 and the second part of feature 3 from Robinson's list cannot apply to pp. 213-28 of the gathering. As for the use of a different handwriting, it is clear from Robinson's feature 3 that this is no conclusive evidence for a booklet. Feature 4 does not fit, either, because Raw ([1984] 1994, 254; 256; 263 et passim) has shown that the sheet and leaves lost in the part of gathering 17 containing Christ and Satan were very probably meant to contain illustrations according to an editorial plan common to that of Liber I. Feature 6 does not fit, either, as I will show later ${ }^{17}$. And finally, the diverging number of leaves in gathering 17 (s. feature 7) turns out not to be relevant because the portion with Christ and Satan does not form a unit structurally independent from the rest of the gathering.

All of Bischoff's and many of Robinson's booklet examples bear the signs of having been folded. Thus, we must treat creases as possible hints for a booklet. Let us now closely analyse the horizontal crease in gathering 17 in order to show that it cannot be taken as evidence that the part of the gathering affected by it has ever been a booklet.

\section{The Crease in Gathering 17}

According to Raw ([1984] 1994, 269), the crease in gathering 17 affects two of the three original bifolia (pp. 213/214-227/228; pp. 215/216-225/226) to-

16 On top of p. 217 the text (1. 171 of Christ and Satan) begins in midsentence; the text at the bottom of p. 224 (1. 527 of Christ and Satan) end in midsentence, too.

17 In par. 4. of the present study. 
gether with the added portion of the gathering, i.e. that part of the gathering that Raw holds to have been added to the original gathering structure when Christ and Satan was set down ${ }^{18}$. From Raw's words, it follows that the only part of gathering 17 that is not affected by the crease is the outmost bifolium of the gathering (pp. 211/212-229/(230)) ${ }^{19}$. Raw (ivi) dates this crease as contemporary with the early $13^{\text {th }}$ century re-sewing of Junius 11 on grounds of the following codicological evidence:

The crease is in precisely the same position on all leaves. It lies exactly half-way down the page and is much looser at the edges of the leaves than it is near the spine, showing that it was made from the spine outwards. The outer two bifolia in the gathering were moved sideways when the manuscript was re-sewn and the original stitch-line on these sheets is now about $5 \mathrm{~mm}$ to the left of the stitching. The tightest part of the crease lies across this area, showing that the crease was made after these sheets had slipped sideways. The crease must therefore date from the time of the re-sewing of the manuscript.

This is also confirmed, in my view, by the position of the crease on the stub between pp. 216 and 217, corresponding to the conjunct leaf 223/224. Here, too, the tightest part of the crease does not lie on the original stitchline (i.e. starting from there outwards), but across it. This means that the remaining singleton had already slipped leftwards when the crease was made. Thus, either the crease was made right after the sheets had slipped sideways and directly before they were re-stitched, or right after they were re-stitched, but anyway before the re-sewn gathering was attached to the binding boards ${ }^{20}$.

The early $13^{\text {th }}$ century dating for the crease is per se substantial evidence against the booklet thesis. Nevertheless, some authoritative scholars such as Doane $(2013,3)$ still follow Lucas' view ${ }^{21}$ : therefore I will discuss every single aspect of this issue.

If the crease was caused right after the re-stitching, the crease itself is expected to have affected the whole gathering, including the outmost sheet (pp. 211/212 and 229/(230) ${ }^{22}$. Superficially it looks as if it has, at least in the

18 This added portion consists of the inner singletons (pp. 217/218; pp. 223/224) and the innermost bifolium of the gathering (pp. 219-22). See above (par.1. of the present study).

19 Needless to say, we are not able to find out whether the supposed lost bifolium (between pp. 212 and 213 and between pp. 228 and 229) was affected by the crease or not.

20 In both cases this would imply an interruption of the re-sewing and binding process during which that part of the gathering was kept folded for some time for aims unknown to us.

21 Doane (ivi) defines Lucas's reconstruction of the codicology of gathering 17 as "convincing", but he does not state why.

22 In fact, the inner part of the gathering was never sewn independently from the outmost bifolium; all sheets (leaves and bifolia) in gathering 17 were stitched together simultaneously, both in the earliest sewing and in the re-sewing. See Raw ([1984]1994, passim). 
spine area. In the image of gathering 17 in the digitized link of the Bodleian Library as well as in Muir (2004) the crease is clearly recognizable not only on two of the three original bifolia and on the folia of the added section ${ }^{23}$, as Raw indicates, but also, it seems to my eyes, on the outmost sheet, that is, on pp. $211 / 212$ (more markedly in the latter) and on pp. 229/(230) (more markedly in the former, maybe because p. (230) is very dirty and crumpled.). There a light crease lies clearly in the spine area and possibly on the outside margins (this is difficult to judge from the digital image). One alternative explanation for the crease near the spine on the outmost bifolium could be gathering 17 being joined to a binding board right there.

The presence of the crease on the outmost bifolium is not stated by Raw, according to whom the crease affects only "the added portion together with two of the original bifolia” (Raw [1984] 1994, 269). Gollancz (1927, xcix), too, notices that "the manuscript of Christ and Satan shows a ridge caused by its leaves having been folded across the middle." According to him, "[t]he ridge in question has affected pp. 229-30, and has also been communicated to a good many pages in Book I" (ivi). Gollancz's words do not clearly explain his use of the verb affect, i.e. they do not unequivocally point out whether in his view the ridge on the outmost bifolium (pp. 212/212 and 229/(230)) has been caused by this bifolium having been folded together with the other sheets (bifolia and singletons) of the gathering, or if it is, say, just an imprint left by the 'proper' ridge after the folded sheets of Christ and Satan had been unfolded and re-stitched together with the outmost bifolium. This might have been the case, too, with the pages in Book I that Gollancz refers to by stating that the ridge on the manuscript of Christ and Satan "has also been communicated to them" (ivi, s. above) ${ }^{24}$. In any case, Gollancz, too, notices a crease on the outmost bifolium on the same position in the spine area as in the inner pages.

A more accurate look at the features the crease takes on in the pages of the gathering may suggest a reasonable answer to the issue of whether the crease in the spine area on the outmost bifolium (pp. 211/212 and 229/(230)) has the same origin as the crease in the inner part of the gathering or not. The crease on the outmost bifolium (pp. 211/212 and 229/(230)) looks much lighter than that in the first inner bifolium (pp. 213/214 and 227/228). The notable difference between the depth of the crease in both bifolia cannot be explained only through a bifolium having gone lost between them ${ }^{25}$.

23 All images of MS. Junius 11 in the present article are drawn from the Bodleian digital facsimile of the manuscript (by courtesy of the Bodleian Library). The evidence I provide through the photographic details in the present article is best visible at the website itself. <http://image.ox.ac.uk/ show? collection=bodleian \&manuscript $=$ msjunius $11>($ accessed 15/12/2014).

24 See also Lucas $(1979,49)$, below in this paragraph.

25 On the loss of a bifolium in gathering $17 \mathrm{~s}$. above, par. 1 in the present study. 
If one considers each single open bifolium in gathering 17 (after opening it up), one can unmistakably notice two facts. First, the crease in the outmost bifolium is less evident than in all others. Second, in all inner bifolia (i.e. all bifolia inside the outmost one), the crease in the left leaf in each open bifolium always looks more 'ramifying' than in the conjugate right leaf, since the crease in the left leaf usually consists of a two- or threefold line, whereas in the right leaf it always looks more linear, more like a neat line across the page. Here the crease in the first inner bifolium (pp. 213 on the recto / 214 on the verso and 227 on the recto / 228 on the verso) is given:

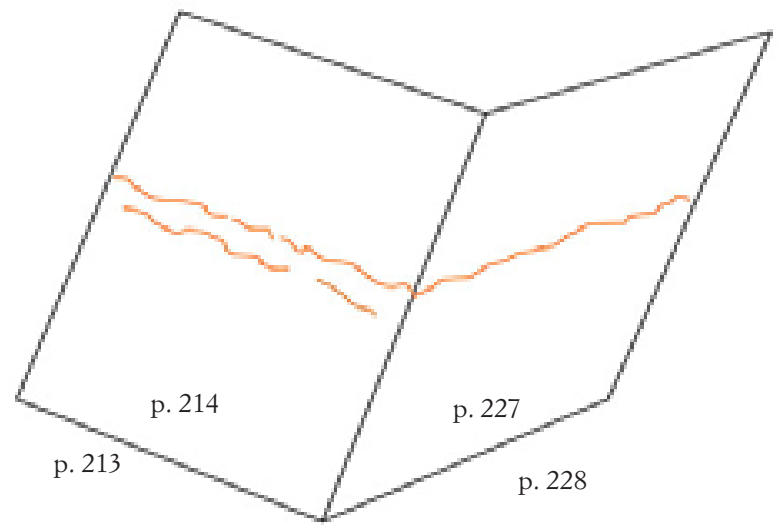

Fig. 2 - The crease scheme in the first inner bifolium.

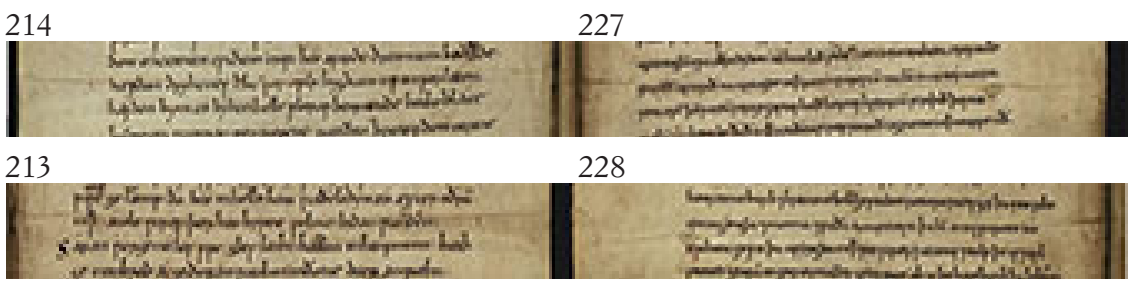

Fig. 3 -MS. Junius 11, pp. 213, 214, 227, 228. The crease in the first inner bifolium.

As I have stated, on the left side pages (pp. 213/214) the crease forms a twofold or multiple line, whereas on the right side pages (pp. 227/228) it consists of a single neat line. All bifolia in gathering 17 except the outmost bifolium follow this 'multiple left side vs. simple right side'-scheme ${ }^{26}$.

26 The constraints of the present format do not allow me to reproduce the crease scheme in all bifolia 
These facts lead to two conclusions. First, the crease in the outmost bifolium of gathering 17 has a different origin than the crease in the inner ones, since the former looks on the whole much fainter and - which is even more relevant - shaped too differently. If the outmost bifolium had been kept folded together with the others, we should expect it to show the same crease structure as the others (two- or three fold crease on the left half sheet vs. simple crease on the right half sheet). We should also expect it to have in its two halves the deepest and the faintest crease of the gathering (respectively, the deepest one across the left half sheet and the faintest one across the right half sheet).

The second conclusion is quite a qualified one for now because it will need a hands-on analysis of the manuscript to be confirmed. As can be gained from the digitized images from Muir (2004) and from the Bodleian link, the folding angle of the parchment in the crease area strongly suggests that the gathering (except the outmost bifolium) was folded with p. 213 outside and p. 228 inside. Thus, very probably the two- or threefold crease, that is, the larger crease area was outwards in the folded gathering, the neat one inwards.

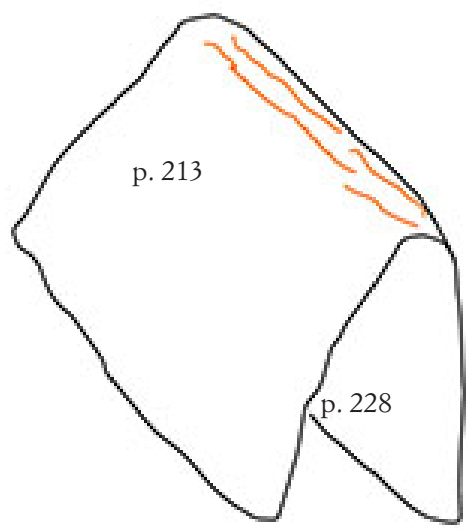

Fig. 4 - Reconstruction of the folded sheets.

According to Lucas $(1979,49)$, the crease proper affected only the sheet corresponding to pp. 213-28 and the sheets and singletons inside it; he considers this to be the "inner quire" (ivi) originally folded like a booklet:

Pp. 213-28 were originally folded very sharply at line 16 , i.e. across the middle of the page, with the present leaf 2 on the outside and leaf 9 on the inside, and this crease

except the outmost one; however, it is recognizable in Muir 2004 and in the Bodleian images on the quoted webpage. 
has been reflected on to the outer leaves (pp. 211-12, 229-30) during the long period of time that the leaves have been bound up together. From an examination of the manuscript it is clear that pp. 213-28 were creased (i.e. folded and unfolded) but that the corresponding 'ripple' in pp. 211/212 and 229/230 is not a crease, merely a 'reflection' of the crease in pp. 213-28. The crease has also been communicated through pp. 211-12 to the preceding quire.

My reconstruction of the folding structure, with p. 213 as the outmost folded page and p. 228 as the innermost folded page ${ }^{27}$, corresponds to Lucas's reconstruction of the folding direction ${ }^{28}$. Nevertheless, to my eyes the ridges on some of the pages (e.g. p. 214) look as if the 'booklet' might have been folded at least once in the opposite direction, too (i.e. with page 213 inside and p. 228 outside).

Whatever origin we may suggest for the crease on the outmost bifolium of gathering 17 - it possibly being an imprint of the 'proper' crease or a mark of the gathering being tightly bound to one board right there - it cannot invalidate Raw's ([1984] 1994, 269) conclusion that the crease in the inner part of the gathering (from p. 213 to p. 228) was caused after the slipping sideways of the bifolia (and, I should add, of the said singleton of pp. 223/224, too) in connection with the $13^{\text {th }}$-century re-sewing - probably, directly before the resewing. Raw's reconstruction also shows that the crease was later than the first sewing of Junius 11 in the $11^{\text {th }}$ century. Thus, according to this evidence the crease is not due to a supposed $11^{\text {th }}$-century circulation of the Christ and Satan sheets in the form of an originally separate booklet ${ }^{29}$. As to the possible aims of such a folding, Raw ([1984] 1994: 269-270) admits: "Why this part of the manuscript should have been folded remains a mystery."

Gollancz, too, has focussed on the issue of the dating of the crease. $\mathrm{He}$ suggests a relative dating by arguing against Clubb $(1925, \mathrm{xv})$ that the writing came after the folding ${ }^{30}$ :

Professor Clubb states, erroneously in my opinion, that the folding succeeded the writing. [...] I am convinced that the contrary was the case. The script just above the folds shows the characteristics incident to such a condition of the parchment. Certain lines, e.g. pp. 226, 227, 228, 1. 16, show the cramped style due to the scribe's avoidance of the ridge, and so with lines in the same position on other pages. The ridge

27 We do not know whether the supposed lost bifolio in the original gathering was folded or not, so actually pp. 213 and 228 are, in my scheme, respectively the outside and inside page of the folded portion.

28 In fact, "the present leaf 2" (Lucas 1979, 49), which in Lucas's view was on the outside, corresponds to pp. 213/214 and "leaf 9" (ibid.), which in his view was on the inside, corresponds to pp. 227/228.

29 I am not able to check the position of the crease on the stub corresponding to the other singleton (pp. 217/218) because it is not clearly visible on the Bodleian link or in Muir (2004).

30 On this point s. also Clubb (1928, 304-06). 
in question has affected pp. 229-30, and has also been communicated to a good many pages in Book I. From this it may be inferred that the ridge in the leaves inserted between the first and the last leaves of the gathering (which had belonged to Daniel) preceded the writing. (Gollancz 1927, xcix)

Here follows a section of the digital images from the Bodleian link of the pages (pp. 226, 227, 228, 1. 16) Gollancz takes as evidence for his relative dating. What we see on line 16 contradicts Gollancz's claim ${ }^{31}$ :

p. 226, line 16 "help..."

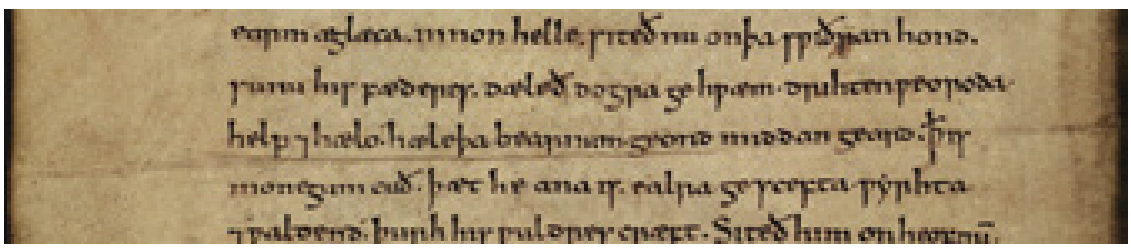

p. 227 , line 16 "gecw..."

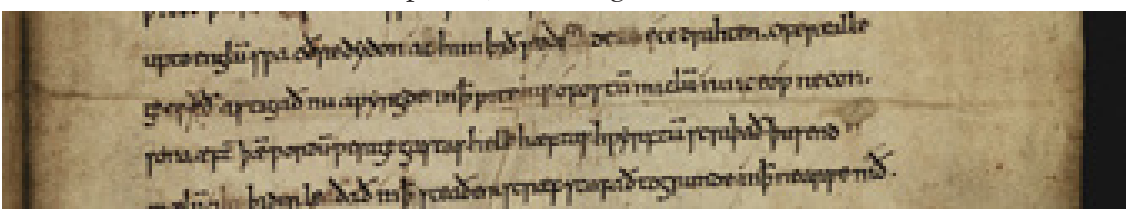

p. 228 , line 16 "cyning..."

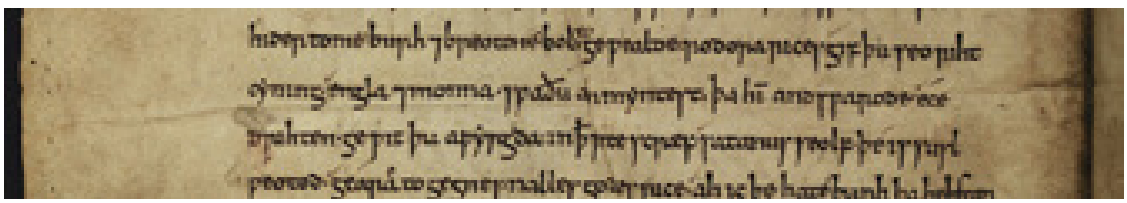

Fig. 5-MS. Junius 11, line 16 on pp. 226, 227, 228.

To me, script in line 16 does not look more cramped than in other lines in those very pages ${ }^{32}$; on the whole, I can find no evidence that the writer tried to avoid the crease (for instance by writing along the crease instead of along the ruled line).

31 I would like to thank prof. Emanuele Bertoni of the Accademia di Belle Arti di Urbino for his great help in preparing the photographic details for publication.

32 The issue of whether the handwriting looks cramped or not, or whether it looks more cramped at one point in the page than at another, is often a matter of subjective perception, since the quality of being cramped cannot be univocally 'measured'. The last word as to these lines being cramped or not should be left to the reader of this study. 
Generally speaking, the contrary seems the case throughout the pages affected by the crease ${ }^{33}$. Here follows just one of the many possible instances from one of the pages affected by the crease. It is a detail of the crease in the right side of p. 213:

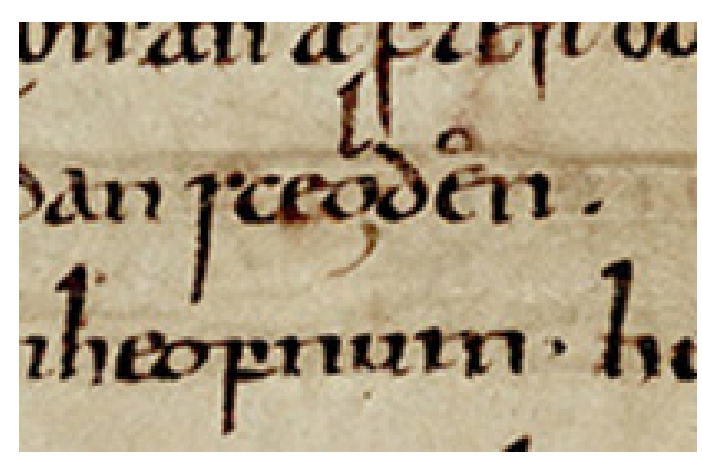

Fig. 6-MS. Junius 11, p. 213, crease on line 16, detail.

The crease on p. 213 cuts through the words of line 16. One of them, sceoden, was corrected into sceoldon by adding $l$ and $o$ above. As is clearly visible, the crease cuts through this correction-o. Given the plenty of space above sceoden, the corrector could have easily avoided the crease by adding the $o$ a couple of $\mathrm{mms}$ above the crease. This is firm evidence that the crease is later than both the correction and the main text script; thus, the leaf was already written when it was folded.

Clubb's conclusion that the folding followed the writing confirms in Lucas's $(1979,49)$ eyes the correctness of his own thesis that leaves 2 to 9 (i.e. pp. 213 to 28) must have had a separate existence in the form of a booklet before they were inserted into quire 17 of MS Junius 11. As a further confirmation for his booklet's thesis Lucas refers also to Clubb's $(1925,35)$ argument that some of the letters (especially those with ascenders) in line 16 of pp. 226, 227, and 228 - i.e. in Lucas's $(1979,49)$ view the innermost pages in the folded booklet - "have become partially indistinct through repeated folding and unfolding of the parchment" (ivi). This explanation of the fading ink is shared by Remley $(1996,21)$, according to whom nobody has yet countered this argument.

Apart from the fact that "repeated folding and unfolding" in itself does not demonstrate the booklet thesis, as I have shown, and that pp. 226, 227 and

33 The reader should verify this personally through the help of the magnifier in Muir (2004) or in the quoted Bodleian link. 
228 being inside the folded 'booklet' would be in itself no reason enough for the letters on their crease to be more damaged than those on the crease in the outer leaves, we should also note that Lucas's and Remley's are no conclusive evidence for a further reason. Careful observation of the MS pages gives ample evidence that letters and their ascenders situated on a crease or next to it may become partially indistinct in ways other than through repeated folding and unfolding of the parchment (and, conversely, that folding and unfolding in itself does not necessary cause ink loss). I will now show that ink in MS Junius 11 easily fades away when it finds itself on any kind of uneven surface (be it a ridge, a relief, or a furrow) and is thus permanently exposed to contact to other surfaces (for instance, to the parchment of the opposite page) or it had not been properly absorbed in the parchment (for instance when a letter was written on the furrow side of a ruling). I will give here only some of the many instances in MS Junius 11 when a part of a letter has lost its ink and suggest for each case an explanation for this loss, and finally compare it with the letters on the crease in pp. 226, 227 and 228 as well as on the further 'booklet' creases.

Let us start from gathering 17. The following two details are from p. 212, which belongs to the original quire 17 but apparently was not folded into the supposed 'booklet'. In these cases it is clear that ink faded away from the letters at the place when they cross the relief side of the ruling. See for instance $g$ in æ⿸elinga, the second $o$ in snotor, the $g, s$ and $e$ in gaste, the whole word gyf, the $f$ in staf and so on:

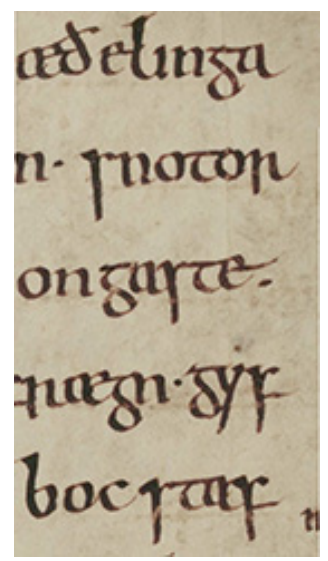

Fig. 7 -MS. Junius 11, p. 212, right margin, right end of lines 3-7.

See again on p. 212, left margin, first word of line 18. Here, too, the ink has faded from the relief side of the ruling: 


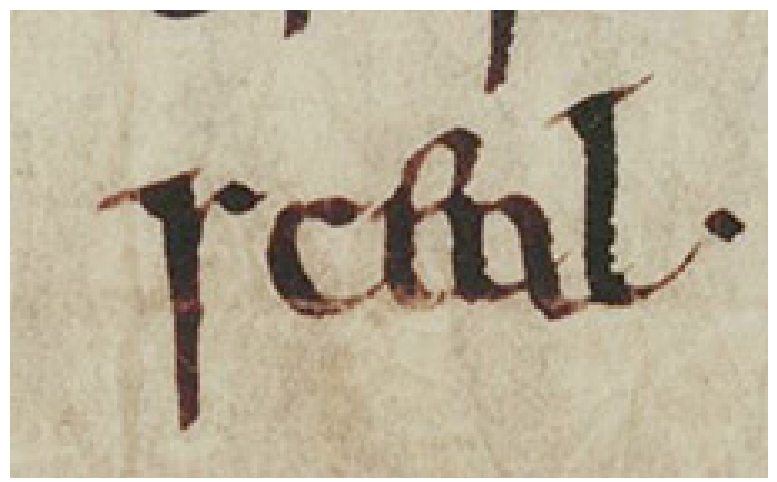

Fig. 8 -MS. Junius 11, p. 212, left margin, first word of line 18.

Again on p. 212, here on the last line, we have relief-caused fading of the ink. Here, too, the relief side has caused the ink fading away from the basis and the ascenders of several letters:

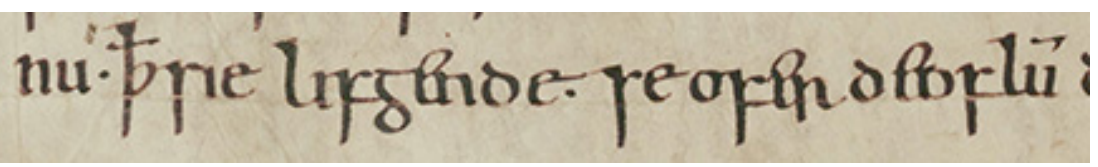

Fig. 9-MS. Junius 11, p. 212, the bottom line.

The relief of a ruling causes the corresponding ink being permanently exposed to other surfaces and thus it possibly fading away. In this, it behaves similarly to a ridge or a crease, which is itself a relief. If ink is on a ridge, it tends to fade away on grounds of its being on a relief and thus exposed to other surfaces. This is reason enough for ink to fade away; repeated folding is another possible but not necessary cause for ink loss.

Let us examine some instances of ink fading away from ridges in gathering 17. On some of the inner leaves an oblique ridge is to be found respectively on the upper right corner of the recto page and on the upper left corner of the verso page. How it originated is not clear, but given the presence of similar oblique ridges on analogous positions in other gatherings (e.g. pp. 13/14; pp. 83-87, gatherings 3 and 7) we cannot hold this oblique ridge in gathering 17 as further evidence for an independent booklet circulation of that gathering portion. Here is one portion of the oblique crease on the right upper corner of a recto page, p. 217: 


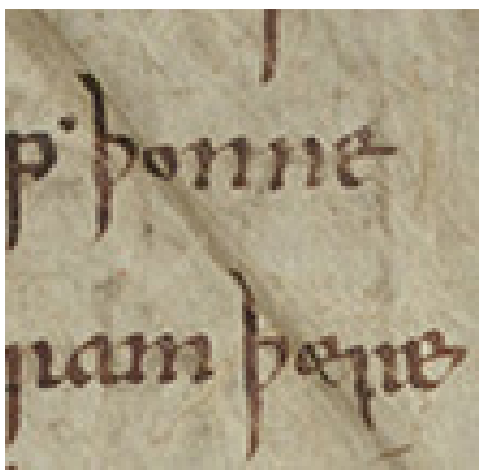

Fig. 10 - MS. Junius 11, p. 217, right end of lines 3 and 4.

The ink on the ascender of the lower $p$ and on the middle of the upper $p$ has crumbled away in correspondence of the crease, even though this crease is not the supposed 'booklet crease', i.e. it is not the horizontal crease across the page which Lucas holds to have been repeatedly folded and unfolded. This oblique crease was quite surely not "repeatedly folded and unfolded" and has nevertheless lost its ink.

The second instance from p. 217 is a vertical crease starting about from line 16 - the line affected by the supposed horizontal 'booklet crease' - and ranging down to line 22 . This vertical crease cannot have been repeatedly folded and unfolded, nevertheless the letters affected by it, such as the $o$ in feond (line 18), the $t$ in to (line 19), the $e$ in waldend (line 20), have lost their ink and the parchment corresponding to the crease looks almost as worn out as if it might have been folded and unfolded more than once:

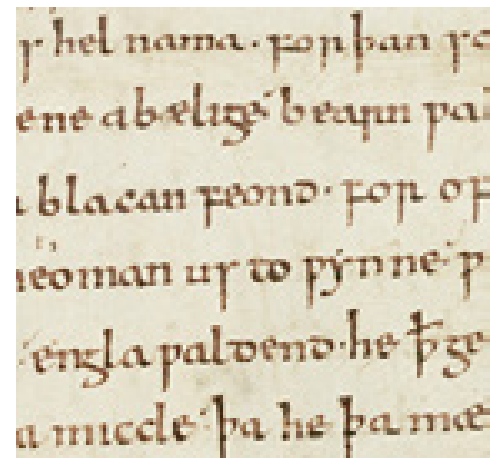

Fig. 11 - MS. Junius 11. A vertical crease on p. 217. 
Similarly, on p. 223 a bulge in the lower right corner of the page has caused ink loss from the corresponding words even though the bulge itself was not repeatedly folded and unfolded:

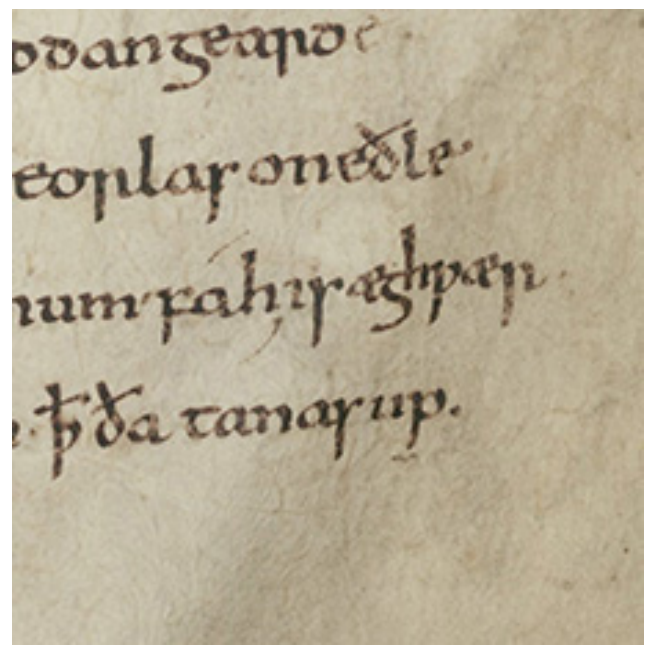

Fig. 12 - MS. Junius 11. A bulge on p. 223.

The same can be said about ink loss from a bulge on the upper right corner of $\mathrm{p}$. 224. Although the bulge was not "repeatedly folded and unfolded", the ink loss there looks very much the same as from the 'booklet crease':

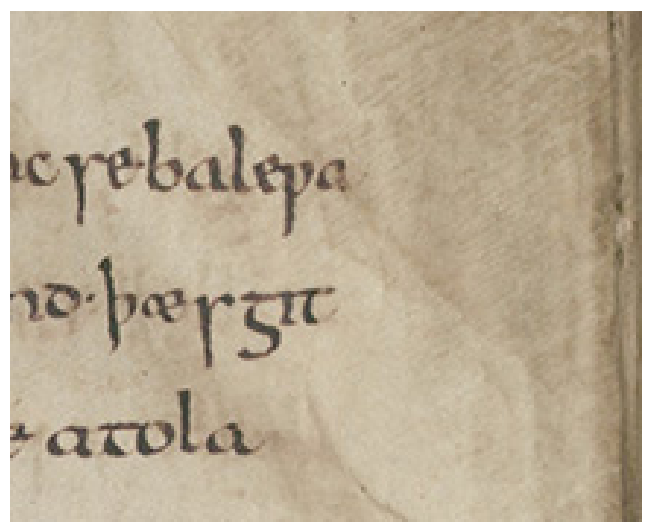

Fig. 13 -MS. Junius 11. A bulge on the upper right corner of p. 224. 
Evidence from gatherings other than 17 are even more interesting, because those gatherings are not suspected of having ever been folded into a booklet shape, so that creases, reliefs, furrows and other kinds of uneven surfaces as well as ink loss from them are unmistakably due to other reasons than to supposed folding. Let us see some images from various parts of the MS.

In gathering 1, p. 2, lines 24 and 25 give evidence of ink loss both for the letters being written on the relief side of the ruling and for their being crossed by a crease. See the ridge across $p$ in $p a$ (line 24 , right) and the ruling relief across almost all words in line 25:

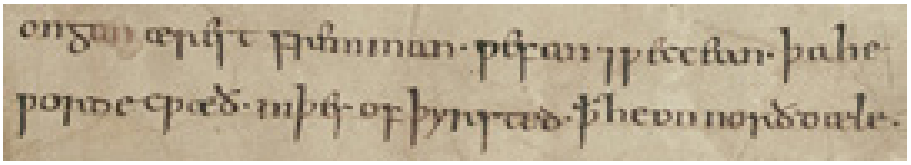

Fig. 14 - MS. Junius 11, gathering 1, p. 1, lines 24 and 25.

On p. 12, gathering 2 , an oblique crease has caused the loss of the ink on the points where the relief of the crease has exposed the ink to contact with other surfaces:

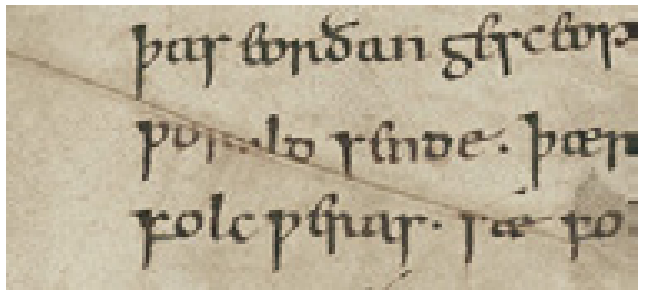

Fig. 15 -MS. Junius 11, gathering 2, p. 12, an oblique crease.

In gathering 3, p. 14, left margin, lines 25 and 26, ink loss is due to the relief of the ruling:

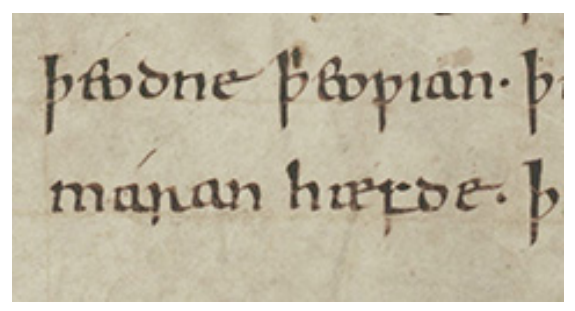

Fig. 16 -MS. Junius 11, gathering 3, p. 14, left margin, lines 25 and 26. 
Evidence of ink loss from letters written on the furrow side of the ruling comes from several pages in the MS, though it is not so often the case as with the relief. This instance is from gathering 4, p. 25, line 1:

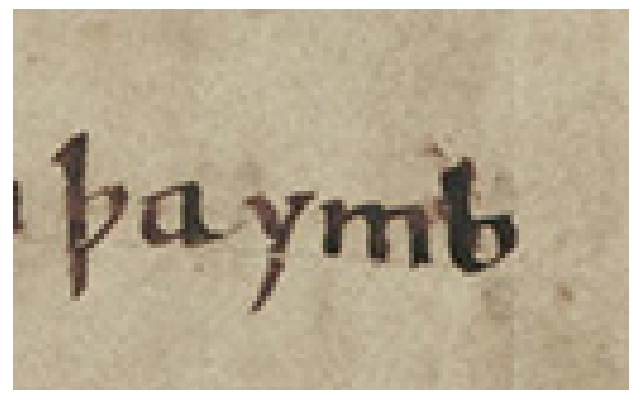

Fig. 17 -MS. Junius 11, gathering 4, p. 25, line 1.

Ink loss along both the relief and the furrow side of rulings is to be found not only on the first and last lines, but anywhere in the page. Here it is on line 9 of p. 26 in gathering 4 (relief side of the ruling):

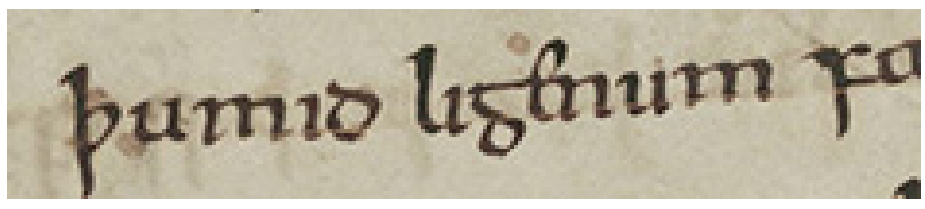

Fig. 18 -MS. Junius 11, gathering 4, p. 26, line 9.

Uneven surface in the form of a bulge, too, causes ink loss, as can be seen on $\mathrm{p}$. 33, gathering 4, line 26. The letters $t$ and $o$ in witod are involved:

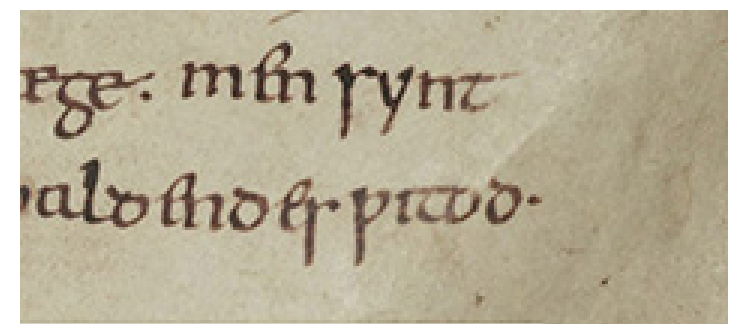

Fig. 19 -MS. Junius 11, gathering 4, p. 33, line 26. 
Evidence from throughout the MS has shown that letters and their ascenders and descenders can become partially indistinct for reasons other than repeated folding and unfolding of the parchment. Some of the examples given above look quite similar to ink loss from the letters on the 'booklet crease'.

With these examples in mind, let us now analyse in detail ink loss from the 'booklet crease' on all leaves. Ink loss will be considered also in connection with the state of the parchment on the corresponding area, in order to analyze any possible hint for "repeated folding and unfolding". I am following the collocation of the pages in each bifolium and singleton in gathering 17, starting from the outmost bifolium of the 'booklet', which contains both its supposedly outmost page (p. 213) and the supposedly innermost page (p. 228):

outmost bifolium (pp. 213/214 - 227/228)

p. 213 (multiple lined crease)

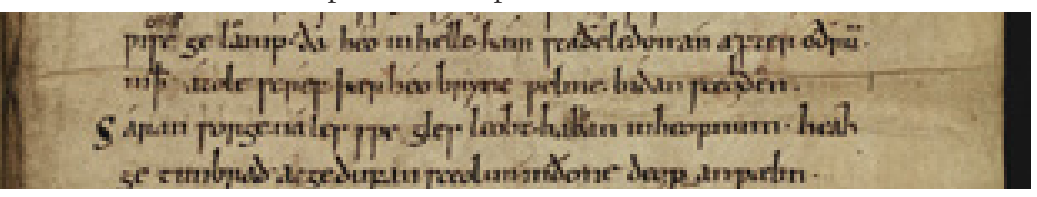

p. 214 (multiple lined crease)

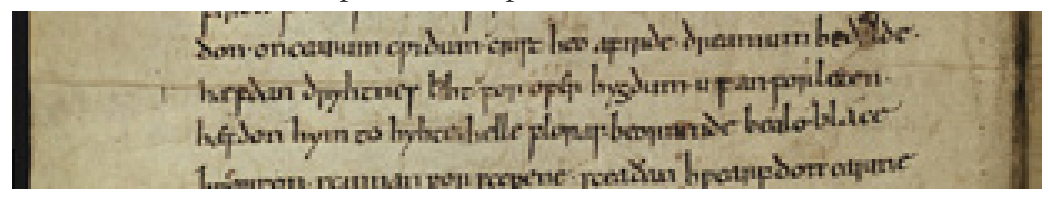

p. 227 (single-lined crease)

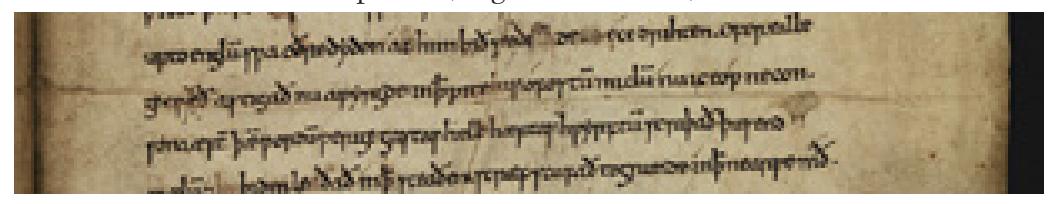

p. 228 (single-lined crease)

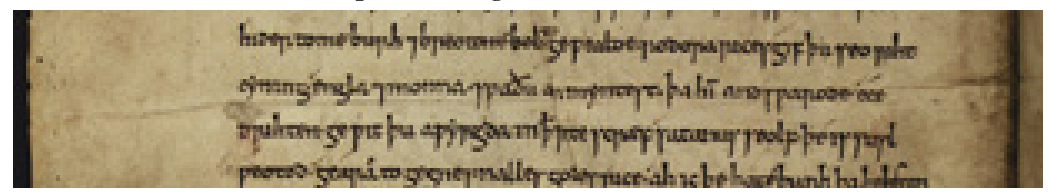

Fig. 20 - MS. Junius 11, crease on the outmost bifolium (pp. 213/214-227/228). 
In this bifolium, only on p. 213 , which is supposed to have been the outmost page of the 'booklet' and has together with p. 214 a multiple-lined crease-type, and on the left half of p. 214, do we find ink loss along most of the crease, but it does not look worse than on other pages in gathering 17 or in the other gatherings. The writing in the crease area can be easily read. On the right side of p. 214 as well as on the other pages ink loss concerns only sporadic groups of letters on the crease and it does not look different from ink loss on other leaves in the MS as they have been shown above. Nor does parchment in this bifolium look particularly worn out in the crease area, which might be the case if it had been repeatedly folded and unfolded.

Bifolium (pp. 215/216-225/226)

p. 215 (multiple-lined crease)

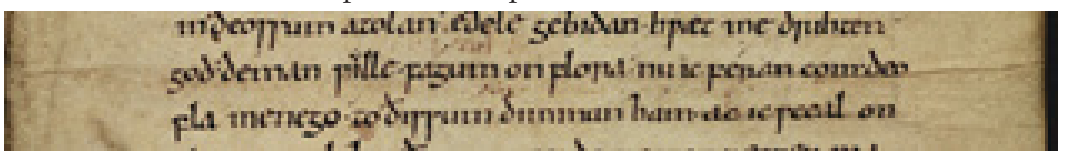

p. 216 (multiple-lined crease)

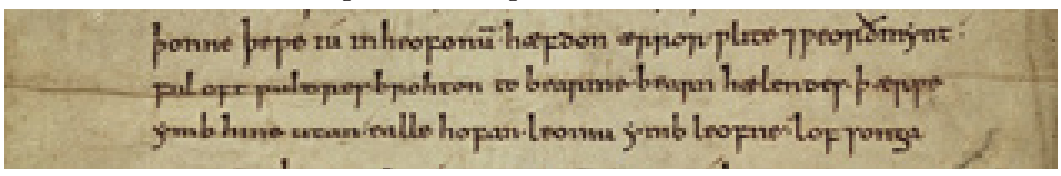

p. 225 (single-lined crease)

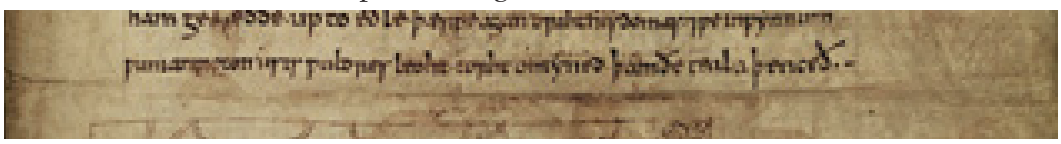

p. 226 (single-lined crease)

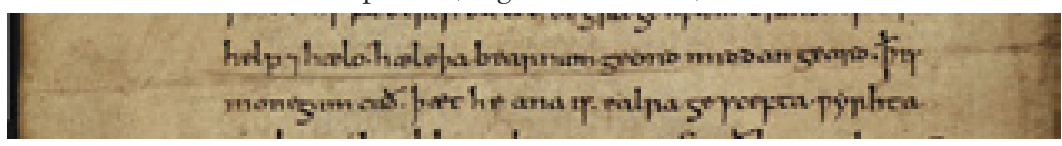

Fig. 21 - MS. Junius 11, bifolium (pp. 215/216-225/226).

On p. 215 ink loss is found especially in the middle of the crease area; on p. 216 letters are still very clearly readable on the multiple-lined crease, even though ink has faded away at different heights from some ascenders and descenders. There are several other long creases, vertical and oblique ones, throughout $\mathrm{p}$. 
216 and ink has faded away along them in a way very similar to ink loss from the central 'booklet crease'. On p. 225 the single-lined ridge looks as though the leaf might have been occasionally folded in both directions; no ink has gone lost, apart from some descenders on the left side of the page. The single-lined ridge on p. 226 looks shorter than on the corresponding p. 225 and not deep. On the whole, p. 226 is in quite a poor state as concerns ink loss. Many letters throughout the whole page look as if ink had crumbled away: the ridge area does not look worse. Along the ridge only some of the ascenders have suffered ink loss.

Singleton (lost conjugate leaf - pp. 223/224)

p. 223 (single-lined crease)

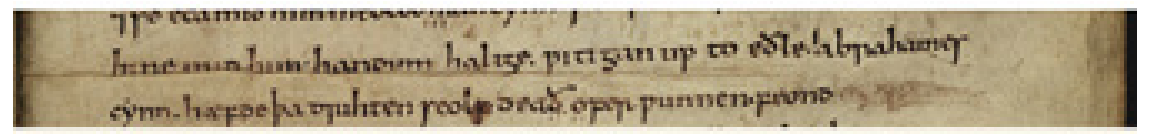

p. 224 (single-lined crease)

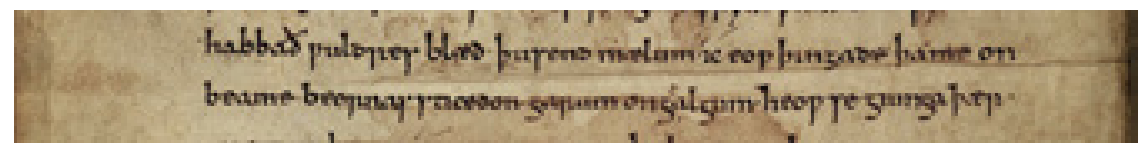

Fig. 22 - MS. Junius 11, singleton (lost conjugate leaf-pp. 223/224).

On p. 223 ink loss from the crease has an aspect analogous to ink loss from the bulge on the lower right corner of the page (Fig. 12), even though the bulge was not repeatedly folded and unfolded; the ridge is quite sharp, except on the right. On p. 224 the very sporadic ink loss is mainly from descenders. It looks similar to ink loss from a bulge on the upper right corner of the page (Fig. 13), for which bulge we may exclude "repeated folding and unfolding".

Singleton (pp. 217/218 - lost conjugate leaf)

p. 217 (multiple-lined crease)

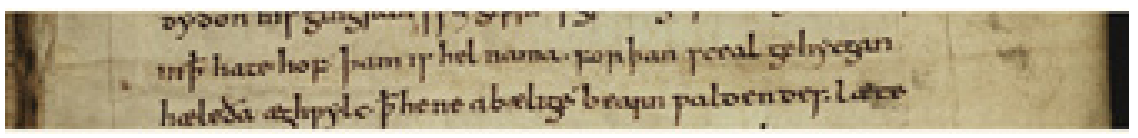

p. 218 (multiple-lined crease)

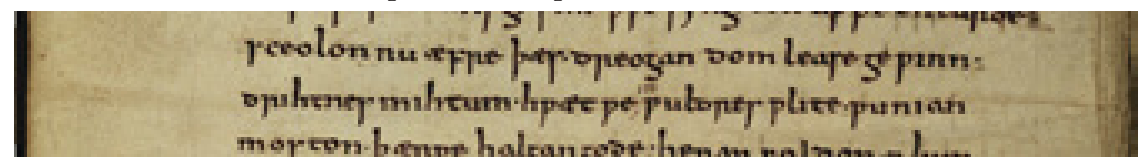

Fig. 23 - MS. Junius 11, singleton (pp. 217/218 - lost conjugate leaf). 
Although parchment in the crease area of p. 217 looks more chapped than in other multiple-lined crease areas, there is little ink loss. Descenders in that area have lost part of their ink in a way similar to those affected by the oblique crease in the upper right corner of the page, which was quite surely not "repeatedly folded and unfolded" (Fig. 10). In any case, ink losses are to be found throughout the whole page, in correspondence to the chaps in the parchment. On p. 218 the multiple-line crease is of course present (in fact it is the verso of the crease on p. 217); however it is barely visible and letters and their descenders are well preserved.

Innermost bifolium (pp. 219/220 - 221/222)

p. 219 (multiple-lined crease)

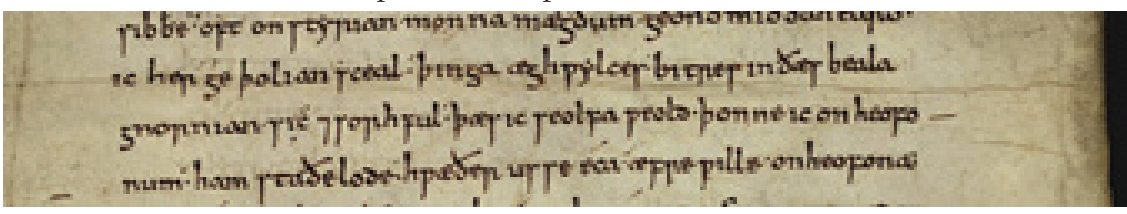

p. 220 (multiple-lined crease)

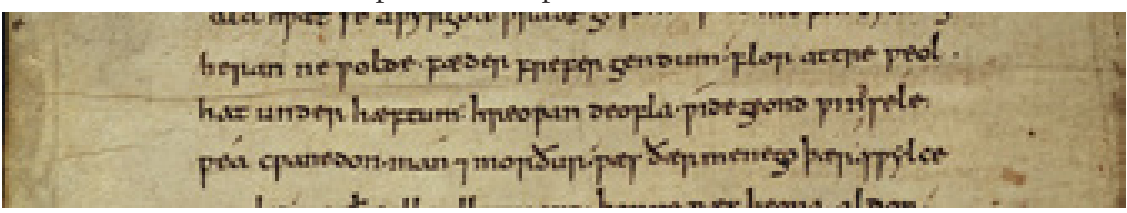

p. 221 (single-lined crease)

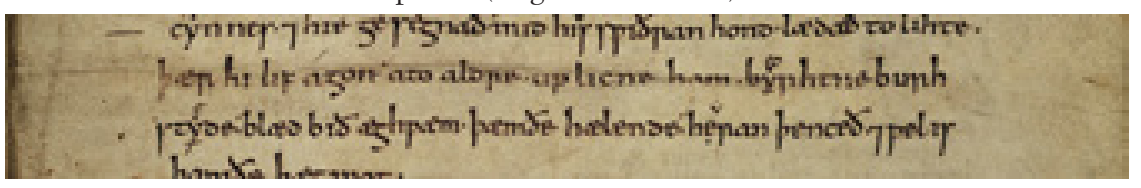

p. 222 (single-lined crease)

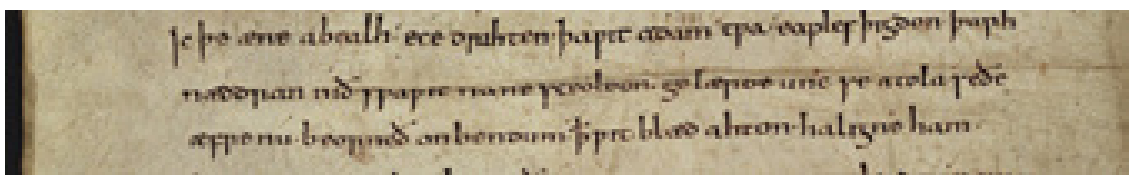

Fig. 24 -MS. Junius 11, gathering 17, innermost bifolium (pp. 219/220 - 221/222).

On p. 219 one of the ridges in the multiple-lined crease is very deep and sharp and the parchment within the crease area is on the whole in a noteworthy 
crumpled state. Nevertheless, ink from letters in that area is surprisingly well preserved. It has gone lost from some points along the ascenders and descenders as well as from the medial letter area, but not so diffusedly as one would expect given the state of the parchment. The crease on p. 220 has the same multiple-lined structure as on p. 219 and the same ridge standing out for its deepness and sharpness. On this page (220) there is no ink loss at all from the crease area. On p. 221, the single-lined crease is quite short but very deep. It cuts through the written line and has caused many letters and their ascenders as well descenders to lose part of the ink. P. 222 looks on the whole in a very bad state, with ridges and ink loss everywhere. On the single-lined 'booklet crease', letters and their ascenders or descenders do not look marred worse than they are through the other creases elsewhere on the page.

\section{CONCLUSIONS}

With all this evidence in mind, we can now draw some conclusions. First, the state of the ink of the letters affected by the supposed 'booklet crease' on the whole is not worse than that of the letters crossed by other creases or written on other kinds of uneven surfaces. In fact, along the 'booklet creases' on several pages no ink loss has occurred. Second, an uneven surface, be it a crease or whatever else, does not necessarily cause ink loss from the letters written on it. Third, ink loss can be caused by letters being constantly exposed to contact with other surfaces and not necessarily by repeated folding and unfolding. From all this it follows that Lucas's claim that ink loss from some letters and theirs ascenders or descenders is evidence for "repeated folding and unfolding of the parchment" must be rejected. Ink loss may derive from repeated folding and unfolding but it is not sure evidence for this, since it can have other origins. This is true even if we consider it in connection with the state of the parchment in the crease area. As we have noticed, parchment in the crease area looks very rumpled only on pp. 217 and 219. Therefore, both ink loss and parchment crumpling through the middle of the supposed 'booklet' pages should be explained in ways other than through "repeated folding and unfolding". If they were due to repeated folding and unfolding, we should expect them to be on all pages affected by the crease, not only on a part of them. I suggest that both ink loss and parchment damage are due to these pages being kept folded into one another for some time, which is quite an unfavourable physical condition for parchment, and that the absence of sewing may have caused the constant switching and rubbing of the folded leaves against one another. They may have been occasionally, but not usually, folded and unfolded. They might have been 
kept unfolded for a while and then refolded into the unsewn 'booklet', maybe in order that a part of Christ and Satan be copied onto another codex before it was definitely re-sewn into MS Junius $11^{34}$. We should note that inside the 'booklet' some leaves are in a worse condition than others, which may suggest that some leaves may have been taken away for a while for some kind of use. A further element against the booklet thesis is the fact that, if p. 213 were the 'cover' of the supposed booklet, we should expect it to look more dirty and ruined, which is not the case. This evidence contradicts Robinson's ([1878] 1994, 27) feature $6^{35}$, unless we posit that the lost bifolium Raw (ibid., 263; 271 et passim) reconstructs between the outside bifolium of the original gathering and the added portion (i.e. the 'booklet') must have once been itself part of the 'booklet' and its left side leaf the 'cover' of the 'booklet' itself ${ }^{36}$. Finally, even if the crease, the state of the parchment in the crease area and the ink loss might indeed derive from "repeated folding and unfolding", this alone would be no conclusive evidence for this part of gathering 17 to have been conceived as $a$ self-contained codicological unit designed for circulating, i.e. as a booklet of the kind Bischoff (1965) and Robinson ([1978] 1994) outline and Lucas (1979) refers to for his thesis.

A codicological issue is never an end in itself. It is related to a manuscript as a living object. Scholarship on Junius 11 in the past forty years has looked at this codex from an editorial perspective and tried to take on the point of view of its original producers and users. The questions whether there was a principle behind the compilation of Junius 11 and whether Christ and Satan was planned to be a part of the compilation from its very inception have long been debated. The outcome of the present study, which provides further evidence against the booklet thesis, seems to confirm the current dominant view: the insertion of Christ and Satan into the manuscript was an early afterthought ${ }^{37}$, but those who copied down this poem intended to make it from the very onset an integral part of Junius 11.

34 The end of Christ and Satan is on p. 229, which is not affected by the 'booklet' crease.

35 See above, par. 2. on early medieval booklets.

36 This would mean that p. 213 was not the outside 'cover' exposed to dirt but it was inside the lost bifolium and thus unexposed. Lucas $(1979,51-22)$ proposes that on the outside of the sheet corresponding to pp. 213/214-227/228 an additional singleton or a bifolium containing on one page the end of Christ and Satan (1l. 710-729) might have existed as an original part of the booklet. According to Lucas's reconstruction (ivi), that singleton or bifolium was then discarded when the 'booklet' was inserted into the manuscript and those lines of the poem rewritten onto p. 219 of gathering 17 (s. above, par. 1 in the present article). But if we accept Raw's analysis, this outmost booklet leaf or sheet cannot ever have existed.

37 When stating that Christ and Satan was an early 'afterthought', we should operate a fine distinction. Physical evidence from gathering 17 strongly suggests that the poem was inserted into the gathering sometime later than the gathering itself had been prepared and Daniel written onto it. Nevertheless, thematic evidence makes me agree with Hall $(1976,41$ and 2002, 66) that the manuscript, which had been evidently conceived 


\section{BIBLIOGRAPHY}

Allen, Marjorie Sue. 1976. The Interior Journey: Monastic Spirituality as Theme and Structure in the Junius Ms. Thesis (Ph.D.), Princeton University, 1976.

Bischoff, Bernhard. 1966-1981. Mittelalterliche Studien. Ausgewäblte Aufsätze zur Schriftkunde und Literaturgeschichte. Stuttgart: Hiersemann. Bd. 1: 1966, Bd. 2: 1967, Bd. 3: 1981.

Bischoff, Bernhard. 1966. „Über gefaltete Handschriften, vornehmlich hagiographischen Inhalts", in: Bernhard Bischoff, Mittelalterliche Studien. Ausgewäblte Aufsätze zur Schriftkunde und Literaturgeschichte. Stuttgart: Hiersemann. Bd. 1, 93-100.

Campbell, Jackson J. 1988. "Ends and Meanings: Modes of Closure in Old English Poetry". Medievalia et Humanistica 16: 1-49.

Clubb, Merrel Dare, ed. 1925. Christ and Satan, an Old English Poem. Yale Studies in English. New Haven: Yale Univ. Press.

Clubb, Merrel Dare. 1928. “The Second Book of the 'Cædmonian' Manuscript”. Modern Language Notes 43 (5): 304-306.

Conner, Patrick W. [1986] 1994. "The Structure of the Exeter Book Codex (Exeter, Cathedral Library, MS. 3501).” Reprinted from Scriptorium 40: 233-42. In Richards ed. 1994, 301-16.

Doane, Alger Nick, ed. 1978. Genesis A. A New Edition. Madison: The University of Wisconsin Press.

Doane, Alger Nick, ed. 1991. The Saxon Genesis. An Edition of the West Saxon 'Genesis B' and the Old Saxon Vatican 'Genesis'. Madison: The University of Wisconsin Press.

from the outset as a biblical compilation, must have been originally planned as a narrative sequence leading to New Testament topics, according to the Christian understanding of the Old Testament as a narration of events prefiguring the New Testament and of its value as "the groundwork it provides for the coming of Christ" (Hall 1976, 41). Two codicological clues suggest that this was the case. First, in the thoroughly planned Liber I a whole quire was prepared as its last gathering, although it must have been clear to the editorial team that the end of Daniel would have filled only some of its pages. It seems then that the remaining space in that quire was planned for a further poem from the very onset. Second, as Lockett $(2002,167-171)$ has pointed out, punctuation in Junius 11 has an antecedent in German, especially Old Saxon biblical poetry: it seems that the scribe of Liber followed the practice of metrical spacing and punctuation shared both by Vaticano, Biblioteca Apostolica Vaticana, Pal. Lat. 1447 (with fragments of the Old Saxon Genesis and Heliand) and Munich, Bayerische Staatsbibliothek, Cgm. 25 (with the Heliand). Lockett's thesis is that this sort of vernacular biblical punctuation may have entered Junius 11 through an exemplar used by the transliterator of the Old Saxon Genesis into Genesis B. We may therefore assume that the editorial team which conceived Junius $11 \mathrm{knew}$ continental biblical manuscripts containing the whole salvation history and planned our manuscript according to their model. In light of this, Hall's (2002: 66) reconciling scenario on the bibliographic unity of Junius 11 seems to me most convincing: what was added as an afterthough was Christ and Satan specifically: however, a New Testament poem must have belonged to the editorial plan of the manuscript since its very inception.

Linguce or - 2/2014

http://www.ledonline.it/linguae/ 
Doane, Alger Nick, ed. 2013. Genesis A. A New Edition, Revised. Medieval and Renaissance Texts and Studies 435. Tempe, Arizona: Arizona Center for Medieval and Renaissance Studies.

Finnegan, Robert Emmett, ed. 1977. Christ and Satan. A Critical Edition. Waterloo, Ontario: Wilfrid Laurier University Press.

Gollancz, Sir Israel, ed. 1927. The Caedmon Manuscript of Anglo-Saxon Biblical Poetry, Junius 11 in the Bodleian Library. Oxford: Oxford University Press.

Gumbert, J.Peter. 2004. “Codicological Units: Towards a Terminology for the Stratigraphy of the Non-Homogeneous Codex". Segno e Testo 2: 17-42.

Hall, J.R. [1976] 2002. “The Old English Epic of Redention: The Theological Unity of MS Junius 11.” Reprinted from Traditio 32: 185-208. In Liuzza ed. 2002, 20-52.

Hall, J.R. 1986. "On the Bibliographic Unity of Bodleian MS Junius 11.” American Notes and Queries 24 (7-8): 104-107.

Hall, J.R. 2002. “'The Old English Epic of Redemption': Twenty-Five-Year Retrospective.” In Liuzza ed. 2002, 53-68.

Hanna III, Ralph. 1986. "Booklets in Medieval Manuscripts: Further Considerations." Studies in Bibliograpby 39: 100-111.

Hill, Joyce. [1992] 2002. "Confronting Germania Latina: Changing Responses to Old English Biblical Verse." Reprinted from Latin Culture and Medieval Germanic Europe. Proceedings of the First Germania Latina Conference beld at the University of Groningen, 26 May 1989, ed. Richard North and Tette Hofstra. Mediaevalia Groningana XI: 71-88. In Liuzza ed. 2002, 1-19.

Junius, Franciscus. 1655. Cxdmonis Monachi Paraphrasis Poetica Genesios ac praecipuarum Sacrae paginae Historiarum, abhinc annos M.LXX. Anglo-Saxonicè conscripta, E nunc primum edita. Amstelodami: apud Christophorum Cunradi. Facsimile edition by Peter J. Lucas. 2000. Early Studies in Germanic Philology 3. Amsterdam-Atlanta (Ga): Rodopi.

Karkov, Catherine E. 2001. Text and Picture in Anglo-Saxon England. Narrative Strategies in the Junius 11 Manuscript. Cambridge Studies in Anglo-Saxon England 31. Cambridge: Cambridge University Press.

Ker, Neil R. [1957] 1990. Catalogue of Manuscripts Containing Anglo-Saxon. Reissued with Supplement. Oxford: Oxford University Press.

Krapp, George Philip, ed. 1931. The Junius Manuscript. The Anglo-Saxon Poetic Records I. New York: Columbia University Press; London: Routledge and Kegan Paul.

Liuzza, R.M., ed. 2002, The Poems of MS Junius 11. Basic Readings. New York and London: Routledge.

Lockett, Leslie. 2002. “An Integrated Re-examination of the Dating of Oxford, Bodleian Library, Junius 11.” Anglo-Saxon England 31: 141-82. 
Lucas, Peter J. 1979. "On the Incomplete Ending of Daniel and the Addition of Christ and Satan to MS Junius 11.” Anglia 97: 46-59.

Lucas, Peter J., ed. [1977] 1994. Exodus. Revised Edition. Exeter: University of Exeter Press.

O'Brian O'Keeffe. 1990. Visible Song: Transitional Literacy in Old English Verse. Cambridge Studies in Anglo-Saxon England 14. Cambridge: Cambridge University Press.

Pasternack, Carol. 1995. The Textuality of Old English Poetry. Cambridge Studies in Anglo-Saxon England 13. Cambridge: Cambridge University Press.

Portnoy, Phyllis. 1994. “'Remnant' and Ritual: The Place of Daniel and Christ and Satan in the Junius Epic.” English Studies 75 (5): 408-22.

Raw, Barbara. 1976. "The Probable Derivation of Most of the Illustrations in Junius 11 from an Illustrated Old Saxon Genesis”, Anglo-Saxon England 5: 133-148.

Raw, Barbara C. [1984] 1994. "The Construction of Oxford, Bodleian Library, Junius 11.” Reprinted from Anglo-Saxon England 13: 187-207. In Richards ed. 1994, 251-75.

Remley, Paul G. 1996. Old English Biblical Verse. Studies in "Genesis", "Exodus" and "Daniel". Cambridge Studies in Anglo-Saxon England 16. Cambridge: Cambridge University Press.

Richards, Mary P., ed. 1994. Anglo-Saxon Manuscripts. Basic Readings. London: Routledge.

Robinson, Pamela R. [1978] 1994. "Self-Contained Units in Composite Manuscripts of the Anglo-Saxon Period." Reprinted from Anglo-Saxon England 7: 231-8. In Richards ed. 1994, 25-36.

Robinson, Pamela R. 1980. “The 'Booklet': A Self-Contained Unit in Composite Manuscripts.” Codicologica 3: 46-69.

Stoddard, Francis H. 1888. "The Caedmon Poems in MS. Junius 11.” Anglia X: 157-67.

Thornley, G.C. 1954. "Accents and Points of MS. Junius 11.” Transactions of the Philological Society 1954: 178-205.

Timmer, Benno J., ed. [1948] 1954. The Later Genesis. Edited from MS. Junius 11. Revised Edition. Oxford: The Scrivener Press.

\section{Digital FACSIMILES}

Early Manuscripts at Oxford University. Digital facsimiles of complete manuscripts, scanned directly from the originals. Bodleian Library MS. Junius 11. <http:// image.ox.ac.uk/show? collection=bodleian \&manuscript $=$ msjunius11 $>$ (last accessed 15/12/2014). 
Muir, Bernhard, ed. 2004. A Digital Facsimile of Oxford, Bodleian Library, MS. Junius 11. Software by Nick Kennedy. CD-Rom. Bodleian Library Digital Texts 1. Oxford: Bodleian Library.

\section{ABSTRACT}

This article deals with a crease in gathering 17 of the Old English MS. Junius 11 (Oxford, Bodleian Library), especially with its possible role as evidence that a part of this gathering may have originated as a self-contained booklet before being bound into the MS. After a critical assessment of scholarship on this issue, the article shows that the crease cannot be considered as a piece of evidence for the booklet thesis and that MS. Junius 11 cannot therefore be defined as a composite manuscript. 